\title{
Unemployment and mortality in Denmark, 1970-80
}

\author{
LARS IVERSEN, OTTO ANDERSEN, PER KRAGH ANDERSEN, \\ KIRSTEN CHRISTOFFERSEN, NIELS KEIDING
}

\begin{abstract}
Relative mortality in the period 1970-80 was studied among Danish men and women who were unemployed and employed on the day of the 1970 census. The study population consisted of the total labour force in the age range 20-64 on 9 November 1970that is, about 2 million employed and 22000 unemployed people. Relative mortality was analysed by a multiplicative hazard regression model (as a natural extension of the standardised mortality ratio) and a multiplicative regression model with extra-Poisson variation.

A significantly increased death rate (40-50\%) was found among the unemployed after adjusting for occupation, housing category, geographical region, and marital state. Analysis of five main causes of death showed increased mortality from all causes, but especially from suicide or accidents. In areas where the local unemployment rate was comparatively high the relative mortality among the unemployed was lower.

The increased mortality among the unemployed was interpreted as a consequence of health related selection as well as increased susceptibility associated with the psychosocial stress of unemployment.
\end{abstract}

\section{Introduction}

The relation between unemployment and mortality has been the subject of research for more than 100 years, particularly the relation

Institute of Social Medicine, University of Copenhagen, Denmark

LARS IVERSEN, MSC, associate professor, sociologist

Central Bureau of Statistics, Copenhagen, Denmark

OTTO ANDERSEN, MA, economist

Statistical Research Unit, University of Copenhagen, Denmark

PER KRAGH ANDERSEN, PHD, associate professor

KIRSTEN CHRISTOFFERSEN, MSC, statistician

NIELS KEIDING, MSC, professor

Correspondence to: Associate professor Lars Iversen, Institute of Social Medicine, University of Copenhagen, Blegdamsvej 3, DK-2200 Copenhagen, Denmark. between unemployment and suicide. In a comprehensive review of unemployment and suicide Platt concluded that the evidence clearly indicated an association, though its nature was undetermined and the role of unemployment in the aetiological process leading to suicide remained to be elucidated. ${ }^{1}$

Platt emphasised the need for longitudinal studies at an individual level. This type of study, however, is difficult. Mortality is low among those of working age. Studies on mortality therefore require large populations, which must be followed up over a long period. Furthermore, data should be collected continually on the study population's employment and health state, making it possible to control for the various selection processes and confounding factors. No such study satisfying all these requirements has been published.

An important step, however, was the study on mortality among the unemployed in England and Wales during the 1970s by Moser et $a l,{ }^{23}$ whose first analyses were published in 1984. They used the longitudinal study population of the Office of Population Censuses and Surveys, which represents a $1 \%$ sample of the population of England and Wales. In this sample roughly 162000 were male (age range 15-64), some 6000 (4\%) of whom were unemployed ("seeking work") in 1971. The mortality in this group was recorded from 1971 to 1981 and compared with that in the whole male population aged 15-64.

After adjusting for social class Moser et al found an excess mortality of $20-30 \%$ among the unemployed. This excess was of the same magnitude in the periods $1971-5$ and 1976-81. In 1986 several supplementary analyses were published. A central result was that areas with comparatively high employment also had high excess mortality. In 1987 a comparative analysis of mortality among the unemployed in the periods $1971-3$ and $1981-3$ was published. ${ }^{4}$ Despite the fact that unemployment was two to three times higher in 1981 than in 1971, the same excess mortality was found among the unemployed. Moser et al concluded that unemployment itself has direct or indirect bearing on mortality and that the reported excess mortality among the unemployed cannot be considered a consequence only of health related selection for unemployment.

We have carried out a similar mortality study on the whole workforce in Denmark at the census in 1970 using public registers. Far more data were available than in Britain and the census comprised both men and women. This paper presents various analyses of mortality from 1970 to 1980 among the Danish unemployed in 1970. 
TABLE I-Categorisation on census form regarding question on employment state on census day

\begin{tabular}{l|l}
\hline \multicolumn{1}{c|}{ People normally in labour force } & \multicolumn{1}{c}{ People not normally in labour force } \\
\hline At work & Housewives \\
Sick & Child \\
Maternity leave & Pupil \\
Unemployed & Student \\
Day off & Pensioner \\
On holiday & Financially independent \\
At a course & Receiving social welfare etc \\
Conscripted & Receiving divorce settlement payments etc \\
\hline
\end{tabular}

$\star$ Part time workers, people helping their spouses, and students in employment considered as being in labour force. not normally in the labour force (109630 men, 671676 women) were excluded from our study. Those who were normally in the labour force were categorised as either unemployed-that is, unemployed on the census dayor employed-that is, those who on the census day were at work, on sick leave, on maternity leave, in the armed forces, on holiday, and so on.

Table II shows the numbers of employed and unemployed people in 1970 and the numbers of deaths between 1970 and 1980. The groups are further stratified by occupation, housing category, geographical region, and marital state in 1970. There were large differences between employed and unemployed people with regard to the four variables.

Cause of death was classified as follows according to the International Classification of Diseases, 1965 (8th revision): malignant neoplasms (codes 140-209), circulatory diseases (390-458), other diseases (000-136, 210-389, 460-796), suicides (E 950-959), accidents (all other E codes).

TABLE II-Numbers of employed and unemployed men and women aged 20-64 at 9 November 1970, numbers of observed deaths during 1970-80, and age, occupation, housing category, geographical region, and marital state of subjects

\begin{tabular}{|c|c|c|c|c|c|c|c|c|}
\hline & \multicolumn{4}{|c|}{ Men } & \multicolumn{4}{|c|}{ Women } \\
\hline & \multicolumn{2}{|c|}{ Employed } & \multicolumn{2}{|c|}{ Unemployed } & \multicolumn{2}{|c|}{ Employed } & \multicolumn{2}{|c|}{ Unemployed } \\
\hline & No & $\%$ & No & $\%$ & No & $\%$ & No & $\%$ \\
\hline Total cohort & 1267289 & $100 \cdot 0$ & 15107 & $100 \cdot 0$ & 717719 & $100 \cdot 0$ & 6659 & $100 \cdot 0$ \\
\hline Observed deaths $1970-80$ & 89139 & $7 \cdot 0$ & 1684 & $11 \cdot 1$ & 23141 & $3 \cdot 2$ & 274 & $4 \cdot 1$ \\
\hline \multicolumn{9}{|l|}{ Age in years: } \\
\hline $20-24$ & 168150 & $13 \cdot 3$ & 3225 & $21 \cdot 3$ & 127599 & $17 \cdot 8$ & 2341 & $35 \cdot 2$ \\
\hline $25-29$ & 178429 & $14 \cdot 1$ & 2045 & $13 \cdot 5$ & 106622 & 14.9 & 982 & $14 \cdot 7$ \\
\hline $30-34$ & 148176 & $11 \cdot 7$ & 1405 & $9 \cdot 3$ & 80397 & $11 \cdot 2$ & 500 & $7 \cdot 5$ \\
\hline $35-39$ & 134750 & $10 \cdot 6$ & 1279 & $8 \cdot 5$ & 77355 & $10 \cdot 8$ & 513 & $7 \cdot 7$ \\
\hline $40-44$ & 135400 & $10 \cdot 7$ & 1254 & $8 \cdot 3$ & 79523 & $11 \cdot 1$ & 513 & $7 \cdot 7$ \\
\hline $45-49$ & 141868 & $11 \cdot 2$ & 1371 & $9 \cdot 1$ & 82776 & $11 \cdot 5$ & 553 & $8 \cdot 3$ \\
\hline $50-54$ & 134361 & $10 \cdot 6$ & 1381 & $9 \cdot 1$ & 72367 & $10 \cdot 1$ & 547 & $8 \cdot 2$ \\
\hline $55-59$ & 124930 & $9 \cdot 9$ & 1633 & $10 \cdot 8$ & 57254 & $8 \cdot 0$ & 444 & $6 \cdot 6$ \\
\hline $60-64$ & 101225 & $8 \cdot 0$ & 1514 & $10 \cdot 0$ & 33826 & $4 \cdot 7$ & 266 & $4 \cdot 0$ \\
\hline \multicolumn{9}{|l|}{ Occupation: } \\
\hline Self employed/helping spouse & 275224 & $21 \cdot 7$ & 114 & 0.8 & 122178 & $17 \cdot 0$ & 15 & 0.2 \\
\hline Non-manual & 380662 & $30 \cdot 0$ & 2078 & $13 \cdot 8$ & 363073 & $50 \cdot 6$ & 2554 & $38 \cdot 4$ \\
\hline Skilled manual & 244954 & $19 \cdot 3$ & 3778 & $25 \cdot 0$ & 8504 & $1 \cdot 2$ & 297 & 4.5 \\
\hline Unskilled manual & 366449 & $28 \cdot 9$ & 9141 & $60 \cdot 5$ & 223964 & $31 \cdot 2$ & 3793 & $57 \cdot 0$ \\
\hline \multicolumn{9}{|l|}{ Housing category: } \\
\hline Owner occupied, all facilities & 576290 & $45 \cdot 5$ & 3620 & $24 \cdot 0$ & 286707 & $39 \cdot 9$ & 1805 & $27 \cdot 1$ \\
\hline Owner occupied, some facilities & 129219 & $10 \cdot 2$ & 2374 & $15 \cdot 7$ & 51107 & $7 \cdot 1$ & 576 & $8 \cdot 6$ \\
\hline Rented, all facilities & 361308 & $28 \cdot 5$ & 3942 & $26 \cdot 1$ & 255459 & $35 \cdot 6$ & 2376 & $35 \cdot 7$ \\
\hline Rented, some facilities & 200472 & $15 \cdot 8$ & 5171 & $34 \cdot 2$ & 124446 & $17 \cdot 3$ & 1902 & $28 \cdot 6$ \\
\hline \multicolumn{9}{|l|}{ Geographical region: } \\
\hline Copenhagen & 199247 & $15 \cdot 7$ & 3079 & $20 \cdot 4$ & 149208 & $20 \cdot 8$ & 1311 & $20 \cdot 4$ \\
\hline North East Sealand & 264203 & $20 \cdot 8$ & 1897 & $12 \cdot 6$ & 159314 & $22 \cdot 2$ & 894 & 12.6 \\
\hline Urban areas & 418721 & $33 \cdot 1$ & 5981 & $39 \cdot 5$ & 234939 & $32 \cdot 7$ & 2817 & $39 \cdot 6$ \\
\hline Rural areas & 385118 & $30 \cdot 4$ & 4150 & $27 \cdot 5$ & 174258 & $24 \cdot 3$ & 1637 & $27 \cdot 5$ \\
\hline \multicolumn{9}{|l|}{ Marital state: } \\
\hline Unmarried & 249399 & $19 \cdot 7$ & 6028 & $39 \cdot 9$ & 134937 & $18 \cdot 8$ & 2561 & $38 \cdot 5$ \\
\hline Married & 947997 & $74 \cdot 8$ & 6774 & $44 \cdot 8$ & 487729 & 68.0 . & 2485 & $37 \cdot 3$ \\
\hline Widowed/divorced & 69893 & 5.5 & 2305 & $25 \cdot 3$ & 95053 & $13 \cdot 2^{\circ}$ & 1613 & $24 \cdot 2$ \\
\hline
\end{tabular}

People resident in hospitals, institutions, hotels, etc are excluded.

*"All facilities" includes central heating, toilet, and bath.

The available data allowed analyses of relative mortality in relation to age, occupation, housing category, geographical region, marital state, and local unemployment rate. We also analysed relative mortality in the periods $1970-80,1970-5$, and $1975-80$ as well as its distribution according to cause of death. All the analyses were carried out separately for men and women.

\section{Subjects and methods}

The census was carried out on 9 November 1970 by means of a self administered questionnaire. Data gathered included age, sex, marital state, housing category, education, occupation, and employment state on the day. These census data were later linked with the Danish registry on causes of death with a view to establishing an occupational mortality register. ${ }^{56}$ This register includes everyone who in 1970 was aged 20-64. At the time of the study the register covered mortality from 1970 to 1980 . The primary objective was to define mortality in relation to occupation in 1970, but in addition to information on occupation the register contains information on employment state on the census day. It may therefore also be used for studies on the relation between mortality and unemployment.

With regard to the question on employment on the census day the questionnaire distinguished between people who were normally in the labour force and those who were not-for example, housewives, students, pensioners, and people receiving social welfare (table I). People who were

\section{STATISTICAL METHODS}

Classical standardisation techniques are usually employed when assessing the effect of unemployment on mortality. A natural extension is multiplicative hazard regression models, ${ }^{78}$ which were used in this study. Results for men and women were analysed separately.

For a person who on 9 November 1970 belonged to age group a and category c (defined by the covariates occupation, housing category, geographical region, and marital state) and who had employment state s (employed or unemployed) the hazard (death intensity) is written as a product of factors depending on acs. For each of the four covariates two types of models were analysed as detailed in the appendix. In the first type of model separate relative death rates for the unemployed in relation to the employed were estimated in each category (c). This is similar to the calculation of standardised mortality ratios for the unemployed in each category, standardising for age and using all people in the labour force in the separate categories as the standard. In the second type of model is estimated a combined relative mortality, corresponding to the calculation of a single standardised mortality ratio for the unemployed, standardising for age and category and using all people in the labour force as the standard. ${ }^{7}$

The parameters and their standard errors were estimated using maximum likelihood and the models tested using likelihood ratio test statistics. Approximate confidence intervals were obtained from the estimated standard errors.

The multiplicative hazard regression models may be extended to include a random component taking account of heterogeneity not explained by the 
factors age (a), category (c), and employment state (s)..$^{90}$ Such models with extra-Poisson variation provide alternatives to the simple multiplicative hazard regression models when these do not explain adequately the variation in the data. Using the models with an extra random component allows a more satisfactory assessment of the uncertainty associated with estimates of the parameters of interest. Typically, estimated standard errors are larger when based on these models. The appendix gives examples of results from the analysis of models with extra-Poisson variation.

\section{Results}

Figure 1 shows for each sex the age specific death rates for each employment state. For both men and women the mortality was higher among the unemployed than among the employed. The ratios between the death rates for the unemployed and employed were higher at lower ages; the differences between the death rates for the unemployed and employed tended to increase with age. When relative mortality for the unemployed compared with employed was assumed to be constant the estimate was 1.58 for men $(95 \%$ confidence interval 1.51 to 1.65$)$ and 1.58 for women $(1.40$ to 1.78). Figure 1 suggests a deviation from the hypothesis of constant relative mortality, which was further supported by the likelihood ratio test statistics ( $p<0.0001$ for men, $p=0.02$ for women). This implies that confidence intervals underestimate the variation, and relative mortality was therefore also estimated in an extra-Poisson variation model (see appendix).

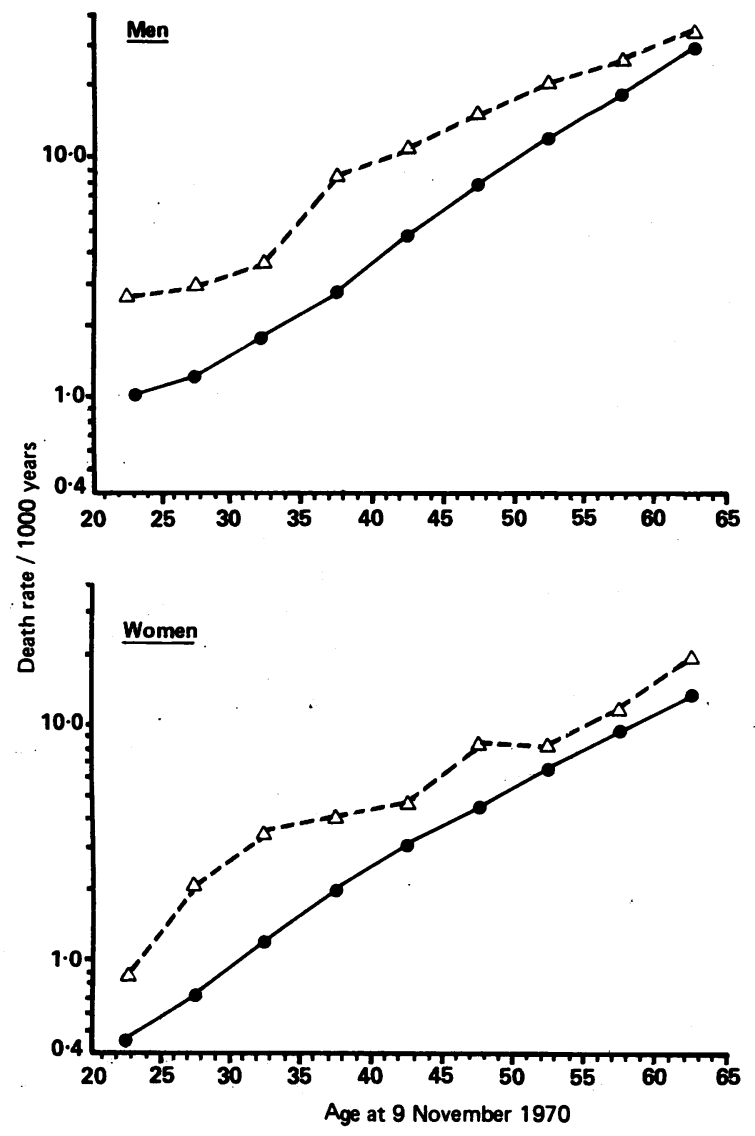

FIG 1-Age specific death rates for employed ( -0$)$ and unemployed $(\triangle \cdots \triangle)$ men and women, 1970-80.

Tables III-VI show the estimated relative death rates for unemployed men and women in models of the two types considered for each of the four factors. As in no case did the models for men provide a satisfactory fit to the data judged from the likelihood ratio test statistic, relative death rates were also estimated in the corresponding extra-Poisson variation models. The appendix gives examples of these calculations, but for ease of presentation and comparison with other studies tables III-VI are restricted to results of the simple multiplicative intensity regression models with (somewhat too narrow) confidence intervals calculated along similar lines as usually done for standardised mortality ratios. Table III shows a smaller relative mortality
TABLE III-Estimated relative death rates for unemployed men and women $(95 \%$ confidence intervals) in separate occupational categories and combined

\begin{tabular}{lcc}
\hline & \multicolumn{1}{c}{ Men } & Women \\
\hline Non-manual & $1.59(1.40$ to 1.82$)$ & $1.75(1.44$ to 2.13$)$ \\
Skilled manual & $1.66(1.50$ to 1.83$)$ & $1.63(0.81$ to 3.29$)$ \\
Unskilled manual & $1.40(1.31$ to 1.49$)$ & $1.37(1.18$ to 1.59$)$ \\
\hline Combined & $1.48(1.41$ to 1.55$)$ & $1.50(1.33$ to 1.69$)$ \\
\hline
\end{tabular}

TABLE IV-Estimated relative death rates for unemployed men and women (95\% confidence intervals) in separate housing categories and combined

\begin{tabular}{lcc}
\hline & \multicolumn{1}{c}{ Men } & Women \\
\hline Owner occupied, all facilities & $1.45(1.30$ to 1.61$)$ & $1.15(0.84$ to 1.55$)$ \\
Owner occupied, some facilities & $1.33(1.18$ to 1.50$)$ & $1.40(0.93$ to 2.11$)$ \\
Rented, all facilities & $1.58(1.43$ to 1.74$)$ & $1.62(1.34$ to 1.97$)$ \\
Rented, some facilities & $1.46(1.35$ to 1.58$)$ & $1.60(1.32$ to 1.95$)$ \\
\hline Combined & $1.46(1.39$ to 1.53$)$ & $1.50(1.33$ to 1.69$)$
\end{tabular}

«"All facilities" includes central heating, toilet, and bath.

TABLE V-Estimated relative death rates for unemployed men and women (95\% confidence intervals) in separate geographical regions and combined

\begin{tabular}{lcc}
\hline & \multicolumn{1}{c}{ Men } & Women \\
\hline Copenhagen & $1.59(1.44$ to 1.74$)$ & $2.06(1.72$ to 2.48$)$ \\
North East Sealand & $1.93(1.69$ to 2.21$)$ & $1.92(1.41$ to 2.62$)$ \\
Urban areas & $1.61(1.49$ to 1.74$)$ & $1.20(0.96$ to 1.50$)$ \\
Rural areas & $1.38(1.25$ to 1.52$)$ & $1.24(0.91$ to 1.70$)$ \\
\hline Combined & $1.57(1.50$ to 1.65$)$ & $1.57(1.39$ to 1.77$)$ \\
\hline
\end{tabular}

TABLE VI-Estimated relative death rates for unemployed men and women (95\% confidence intervals) in separate categories of marital state and combined

\begin{tabular}{lcc}
\hline & \multicolumn{1}{c}{ Men } & Women \\
\hline Unmarried & $1.48(1.34$ to 1.62$)$ & $1.56(1.26$ to 1.94$)$ \\
Married & $1.42(1.32$ to 1.52$)$ & $1.19(0.95$ to 1.49$)$ \\
Widowed/divorced & $1.45(1.32$ to 1.60$)$ & $1.64(1.37$ to 1.97$)$ \\
\hline Combined & $1.44(1.37$ to 1.51$)$ & $1.46(1.30$ to 1.65$)$ \\
\hline
\end{tabular}

for unemployed unskilled manual workers than for non-manual and skilled manual workers, the differences, however, being non-significant for both men and women. For housing category (table IV) there was a non-significant tendency among both men and women towards a higher relative mortality for the unemployed living in rented accommodation than for owner occupiers. For geographical region (table $\mathrm{V}$ ) the relative mortality was non-significantly lower among unemployed men living in rural areas. For women the differences were highly significant $(p<0.0005)$, relative mortality being higher among unemployed women living in Copenhagen and North East Sealand. Finally, table VI shows no effect of marital state on relative mortality among unemployed men, whereas for women there was a tendency $(p=0.07)$ towards a smaller relative mortality among the married unemployed.

In conclusion, the four factors considered had no effect on relative mortality among men, but for women different relative death rates were found in the geographical regions and there was a clear tendency towards a smaller relative mortality for unemployed married women.

The 275 municipalities of Denmark were classified separately for men and women into 10 categories of unemployment rate (range $<0.4 \%$ to $2.0 \%$ ) recorded on the census day (fig 2). In each category the relative mortality among unemployed compared with employed people was estimated. Figure 2 gives the results. In both men and women relative mortality among the unemployed tended to decrease with the unemployment rate. In the simple multiplicative hazard regression models the slopes of the lines approximating the logarithm of relative mortality for unemployment were significantly negative for both sexes. For men the estimated slope was 
$-0.118(95 \%$ confidence interval -0.225 to -0.012$)$ and for women it was $-0.300(95 \%$ confidence interval -0.588 to -0.012$)$. Models with the $\log$ linear effect of unemployment rate on relative mortality did not, however, provide a satisfactory fit to the data, and therefore models with extra-Poisson variation were studied. In these models the tendency towards a decreasing relative mortality for unemployment was also present but the slopes were no longer significantly less than zero.

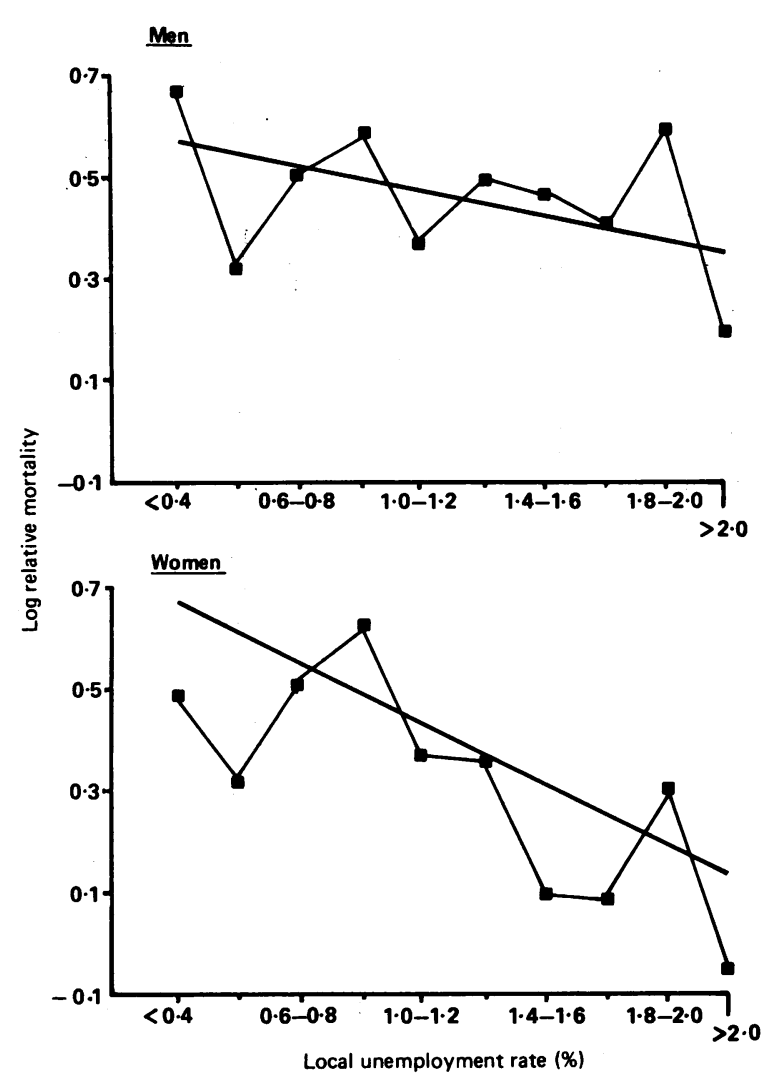

FIG 2-Log relative mortality for unemployed men and women in relation to local unemployment rate in $\mathbf{1 9 7 0}$.

Finally, the relative death rates from various causes were analysed separately for the periods $1970-5$ and $1975-80$ and for the whole period 1970-80. Table VII gives the results for unemployed men and women. Particularly noticeable were the large relative death rates from suicide during 1970-5, which fell during the second period. Relative mortality due to deaths from all causes was also smaller in the second period for both men and women.

\section{Discussion}

Most of our results correspond quite well with the findings of Moser et al. ${ }^{23}$ There are, however, two important differences. Firstly, even after adjusting for occupation we found a higher relative mortality among unemployed men. Probably this was due to the fact that our reference population consisted entirely of employed men, whereas the reference population studied by Moser et al consisted of all males between 15 and 64 years of age. In addition to employed men, their population included those on sick leave, men who had taken early retirement, and so on, who would naturally be expected to have a higher mortality than would our reference population. Another factor may be the high rate of unemployment in the British series as compared with ours (roughly $4 \%$ compared with $1 \%$ ).

The second main difference in our study was the inverse association found between relative mortality and the level of local unemployment-that is, relative mortality among men fell from 1.62 at $1 \%$ unemployment to 1.46 at $2 \%$ unemployment and
TABLE VII-Estimated cause specific relative death rates for unemployed men and women ( $95 \%$ confidence intervals) by calendar period

\begin{tabular}{|c|c|c|c|}
\hline Cause of death & $1970-5$ & $1975-80$ & $1970-80$ \\
\hline \multicolumn{4}{|c|}{ Men } \\
\hline $\begin{array}{l}\text { Cancer } \\
\text { Cardiovascular disease } \\
\text { Other diseases } \\
\text { Accidents } \\
\text { Suicide }\end{array}$ & $\begin{array}{l}1.25(1.07 \text { to } 1.46) \\
1.35(1.18 \text { to } 1.53) \\
2.24(1.88 \text { to } 2.66) \\
2.30(1.83 \text { to } 2.89) \\
2.92(2.33 \text { to } 3.65)\end{array}$ & $\begin{array}{l}1.40(1.24 \text { to } 1.59) \\
1.25(1.13 \text { to } 1.39) \\
2.30(2.01 \text { to } 2.63) \\
2.87(2.27 \text { to } 3.62) \\
2.13(1.65 \text { to } 2.74)\end{array}$ & $\begin{array}{l}1.33(1.21 \text { to } 1.47) \\
1.28(1.18 \text { to } 1.39) \\
2.26(2.04 \text { to } 2.51) \\
2.55(2.17 \text { to } 3.00) \\
2.51(2.12 \text { to } 2.97)\end{array}$ \\
\hline All causes & $1.63(1.52$ to 1.76$)$ & $1.56(1.46$ to 1.66$)$ & $1.58(1.51$ to 1.65$)$ \\
\hline \multicolumn{4}{|c|}{ Women } \\
\hline $\begin{array}{l}\text { Cancer } \\
\text { Cardiovascular disease } \\
\text { Other diseases } \\
\text { Accidents } \\
\text { Suicide }\end{array}$ & $\begin{array}{l}1.25(0.93 \text { to } 1.69) \\
1.60(1.05 \text { to } 2.43) \\
2.99(2.01 \text { to } 4.44) \\
2.19(1.21 \text { to } 3.99) \\
2.46(1.45 \text { to } 4.16)\end{array}$ & $\begin{array}{l}1.08(0.83 \text { to } 1.41) \\
1.31(0.94 \text { to } 1.83) \\
2.32(1.68 \text { to } 3.22) \\
3.27(1.96 \text { to } 5.46) \\
2.44(1.52 \text { to } 3.94)\end{array}$ & $\begin{array}{l}1.15(0.94 \text { to } 1.40) \\
1.41(1.08 \text { to } 1.83) \\
2.55(1.98 \text { to } 3.27) \\
2.71(1.83 \text { to } 4.00) \\
2.45(1.72 \text { to } 3.49)\end{array}$ \\
\hline All causes & $1.71(1.42$ to 2.06$)$ & $1.50(1.29$ to 1.76$)$ & $1.58(1.40$ to 1.78$)$ \\
\hline
\end{tabular}

TABLE VIII-Occupation and relative mortality for unemployed men: results from analyses of simple multiplicative hazard regression models ( $I$ and 2 ) and models with extra-Poisson variation $\left(1^{\star}\right.$ and $\left.2^{\star}\right)$

\begin{tabular}{lcc}
\hline \multicolumn{2}{c}{$\hat{\theta}_{\mathrm{c}}$ (95\% confidence interval) } \\
\hline Model $l$ & Model $l^{\star}$ \\
Non-manual & $1.59(1.40$ to 1.82$)$ & $2.03(1.55$ to 2.66$)$ \\
Skilled manual & $1.66(1.50$ to 1.83$)$ & $2.02(1.58$ to 2.58$)$ \\
Unskilled manual & $1.40(1.31$ to 1.49$)$ & $1.60(1.26$ to 2.03$)$ \\
\hline \multicolumn{2}{c}{$\hat{\theta}(95 \%$ confidence interval) } \\
\hline Combined & Model 2 & Model $2^{\star}$ \\
\hline
\end{tabular}

among women from 1.58 at $1 \%$ unemployment to $1 \cdot 17$ at $2 \%$ unemployment. Moser et al carried out their regional analysis by dividing England and Wales into only three regions and found that in the two regions with the highest level of unemployment unemployed men had the highest relative mortality. The region with the lowest level of unemployment had the lowest relative mortality, but this did not fall outside the confidence intervals for relative mortality in the two other regions. The difference may be due to our analysis being based on 275 municipalities, thereby having a considerably more detailed empirical basis. Figure 2 shows that even on this basis there were large deviations and the association was not unambiguous.

\section{CROSS SECTIONAL UNEMPLOYMENT AS A MEASURE OF EXPOSURE}

The measure of exposure was unemployment at the time of the census in 1970. The group "unemployed" were those who described themselves as unemployed in the census questionnaire. People on sick leave, on maternity leave, in the armed forces, and so on but still in the labour force were not included among the unemployed but were included in the reference population.

An obvious limitation of our measure of exposure is that we did not have information on the duration of unemployment in 1970 or on subsequent unemployment during follow up to 1980.

The unemployed whom we studied were a cross section of the population unemployed at a particular date. Among all people who experienced unemployment during 1970 this group constituted a length biased sample, in the sense that people with a history of long or frequent spells of unemployment had a much greater likelihood of being included than those with few or short periods of unemployment.

On the basis of other studies people who were unemployed at the census date in 1970 may be expected to have had a greater probability of being unemployed in subsequent years than people 
who were not unemployed at the census date. ${ }^{11}$ We cannot support this empirically, but a Danish register on unemployment begun in 1980 contains detailed information on the number of spells of unemployment a year and their duration for all those with unemployment insurance, so that future studies will be able to confirm or disprove this point.

\section{STATISTICAL TECHNIQUES}

Our starting point in choosing statistical techniques was to keep as closely as possible to the convention of using the standardised mortality ratio in studies of occupational mortality. A basic assumption underlying the use of this ratio is that each age specific death rate in the study population (the unemployed) is a constant multiple of that of the standard population (the whole labour force). When this is true a natural extension is multiplicative intensity models. ${ }^{7812}$ We retained this basic framework, though it is readily seen that whereas relative mortality decreased with increasing age, the (absolute) excess mortality increased with age. A project currently in progress will apply a generalised power-function-family of excess death rates, recently suggested by Muirhead and Darby, ${ }^{13}$ which allows an "interpolation" between the two.

Various hypotheses may be constructed to explain the higher relative mortality among the young; for example, it may be a greater trauma for a young person than for an older one to lose his or her job. This substantive interpretation, however, is founded on the essentially completely arbitrary choice of the multiplicative scale for death rates. Had additive excess mortality been measured instead the opposite trend would have been found (see fig 1).

We believe that though interpretation of age interactions such as the above (and possibly also of period effects) should be made with much caution, the main effects obtained here were little influenced by our choice of the traditional scale.

In drawing on the analytical and statistical tools of multiplicative intensity models we also found a lack of fit of the models, at least for men. This has not usually been considered to be an important problem in other work, and indeed the ordinary significance test may not be directly applicable in our series. (Brillinger discussed the role of stochastic models in relation to vital rates. ${ }^{14}$ ) Confidence limits, however, are widely quoted by Moser et al and other workers, and these are equivalent to statistical hypotheses tests, given that the simple proportional hazards model is adequate. As we know this to be false in our series (and suspect that this is also so in many other published studies), in the appendix we supplement the unrealistically narrow confidence limits with tests and confidence limits based on explicit modelling of heterogeneity in the data not accounted for by the multiplicative intensity model. These analyses indicate the same general tendencies as the simple models (in turn equivalent to standardised mortality ratio reasoning) but also emphasise the dangers of too strict a belief in traditional calculations of confidence limits.

\section{ILLNESS AS A CAUSE OF UNEMPLOYMENT ("SELECTION HYPOTHESIS")}

An important problem with our data is the lack of information on health state before the census and the onset of unemployment. This information might shed light on the extent to which illness results in unemployment and thereby contributes to the increased mortality among the unemployed. Inspired by Moser et al, we attempted to assess this indirectly in two ways. Firstly, analyses of the regional variations in excess mortality and unemployment support the existence of health related selection, as the regions with low levels of unemployment also had higher relative mortality among the unemployed.

Secondly, we divided the follow up period into two subperiods, as, on the basis of the selection hypothesis, we would expect a higher relative mortality in the first subperiod and a lower, perhaps no relative mortality in the second. Like Moser et al, we found roughly the same excess mortality in the two subperiods, which supports the suggestion that mechanisms other than health related selection also have an effect. It is hardly conceivable that health related selection in 1970 could explain an unchanged excess mortality five to 10 years later. ${ }^{15}$

\section{SUSCEPTIBILITY AS THE MECHANISM}

Unemployment is a psychosocial stress factor that implies a threat against the identity of the unemployed as well as to their self esteem, social network, and financial security. ${ }^{16-18}$ It is natural in this context to draw parallels with research which has already shown excess mortality among people experiencing psychosocial stress such as poor social network ${ }^{1920}$ or bereavement. ${ }^{21}$

Berkman and Syme pointed to various mechanisms that may determine the association between mortality and the psychosocial stress arising from a poor social network. ${ }^{22}$ These mechanisms are also relevant here.

One possible mechanism may be that people changing from being employed to being unemployed alter their behavinur, thereby raising their mortality. One behavioural change might be, for example, in reducing their use of health services. Apart from the fact that it would be unrealistic to assume that this changed use has such great relevance for mortality, several studies suggest that the unemployed use these services more frequently. ${ }^{23}{ }^{24}$ In Denmark health services are, on the whole, free for everyone, and on the basis of the Danish experience we have no reason to believe that use of the health services by the unemployed changes to an extent that might affect their mortality.

Another mechanism may be that unemployment directly affects physiological processes in the unemployed (for example, increased blood pressure or uric acid concentrations), thus increasing their susceptibility to illness. Studies on physiological variables in unemployed people have noted certain changes, but nothing particularly striking. ${ }^{25-27}$

Lastly, a third and most probable mechanism is the more indirect influence of psychological stress-the susceptibility mechanism. Several longitudinal studies have clearly shown an increased incidence of depressive symptoms, reduced self confidence, and drive. ${ }^{16} 1828$ Thus unemployment increases mental susceptibility, and we must assume that in some people this in turn will increase physical susceptibility. ${ }^{29}$

In our study the excess mortality of the unemployed was almost unchanged in the periods 1970-5 and 1975-80. The explanation may be that the susceptibility mechanism in the first period operated primarily through the reduction of survival time in people selected for unemployment by reasons of health. In the second period further consequences of increased susceptibility might be the outbreak of illness after a certain period of latency.

There are many factors in these theoretical considerations that cannot be illuminated by our study design. There is a need to carry out better controlled longitudinal studies of the selection mechanisms and of the effects of unemployment, particularly on physiological and somatic variables, before we can more accurately determine the possible mechanisms of the excess mortality among the unemployed.

Regardless of the aetiological problems, however, the central result of the study remains: being unemployed on a particular date in 1970 was a sign that the person belonged to a part of the Danish population whose mortality in the 1970 s was increased by $40-50 \%$ compared with people who were employed on that date.

\section{Appendix}

The two types of models for the hazard $\lambda_{\text {acs }}$ analysed for each of the four factors and for men and women separately may be specified as follows. In the first type (model 1) the hazard is written as $\lambda_{\text {acs }}=\alpha_{a c s} \beta_{c s}$. For each category (c) the ratio between the hazards for an unemployed person and for an employed person both belonging to the category and to the same age group (a) is $\theta_{c}=\beta_{c \text {,unemployed }} / \beta_{c, \text { employed }}$, and the relative mortality $\theta_{c}$ is an unemployment effect for category. In the second type (model 2 ) we have $\lambda_{a c s}=\alpha_{a c} \beta_{s}$, and the ratio between the hazards for an unemployed and for an employed person both belonging to age group and category is $\theta=\beta_{\text {unemployed }} / \beta_{\text {employed }}$ for all a 
and c. In this model the combined relative mortality $(\theta)$ is a common effect of unemployment.

These simple multiplicative hazard regression models are equivalent to considering the observed numbers of deaths $\left(D_{\text {acs }}\right)$ in the various cells $(a, c, s)$ as Poisson variates with mean and variance both equal to $\lambda_{\text {acs }} T_{\text {acs }}$, where $T_{\text {acs }}$ is the number of observation years in a cell $(\mathrm{a}, \mathrm{c}, \mathbf{s}){ }^{7}$

In the models with extra-Poisson variation ${ }^{10}$ the $D_{\text {acs }}$ has the same mean but the variance is $\lambda_{\text {acs }} T_{\text {acs }}+\sigma^{2}\left(\lambda_{\text {acs }} T_{\text {acs }}\right)^{2}, \sigma^{2}$ being an additional parameter describing otherwise unexplained variation. Comparing results from analyses of the two kinds of models shows that the estimated standard errors are larger in the model with extra-Poisson variation.

For men the parameters $\theta_{c}$ and $\theta$ were also estimated for each of the four factors in models $1^{\star}$ and $2^{\star}$, respectively, with extra-Poisson variation. As an example table VIII presents the results based on stratification by occupation (see also table III). In table VIII models $1^{\star}$ and $2^{\star}$ show the same general tendencies as models 1 and 2 but the confidence intervals based on the simple multiplicative hazard regression models are considerably narrower. Also the estimated relative death rates $\hat{\theta}_{c}$ and $\hat{\theta}$ are larger in the models with extra-Poisson variation. This is due to the fact that the weighting of the ratios $\hat{\lambda}_{a, \text { unemployed }} / \hat{\lambda}_{a}$,employed was different in the two types of models, the extraPoisson variation model giving comparatively more weight to younger ages (see fig 1 (men)).

\section{References}

1 Platt S. Unemployment and suicidal behaviour: a review of the literature. Soc Sci Med 1984;19.

2 Moser KA, Fox AJ, Jones DR. Unemployment and mortality in the OPCS longitudinal study. Lancet 1984;ii:1324-8.

3 Moser KA, Fox AJ, Jones DR, Goldblatt PO. Unemployment and mortality: further evidence from the OPCS longitudinal study 1971-81. Lancet 1986;i:365-7.

4 Moser KA, Goldblatt PO, Fox AJ, Jones DR. Unemployment and mortality: comparison of the 1971 and 1981 longitudinal study census samples. Br Med $\mathcal{Y}$ 1987;294:86-90.

5 Lynge E. Dødelighed og erhverv 1970-75. Statistiske undersøgelser. No 37. Copenhagen: Danmarks Statistik, 1979.

6 Andersen O. Dødelighed og erhverv 1970-80. Statistiske undersøgelser. No 41. Copenhagen Danmarks Statistik, 1985.

7 Breslow NE, Day NE. Indirect standardization and multiplicative models for rates, with reference to the age adjustment of cancer incidence and relative frequency data. 7 Chronic Dis 1975;28:289-303.

8 Breslow NE, Lubin JH, Marek P, Langholz B. Multiplicative models and cohort analysis. fournal of the American Statistical Association 1983;78:1-12.

9 Pocock SJ, Cook DG, Beresford SAA. Regression of area mortality rates on explanatory variables: what weighting is appropriate? Applied Statistics 1981;30:286-95.

10 Breslow NE. Extra-Poisson variation in log-linear models. Applied Statistics 1984;33:38-44.

11 Pedersen PJ, Smith N. Concentration of unemployment: the Danish labour market 1976-80. Studies in labour market dynamics. Working paper 84-3. Aarhus: Aarhus School of Economics and Business Administration. Institute of Economics, University of Aarhus, 1984

12 Keiding N. The method of expected number of deaths, 1786-1886-1986. International Statistical Review 1987;55:1-20.

13 Muirhead CR, Darby SC. Modelling relative and absolute risks of radiation-induced cancers (with discussion). Foumal of the Royal Statistical Society Series A 1987;150:83-118.

14 Brillinger DR. The natural variability of vital rates and associated statistics (with discussion). Biometrics 1986;42:693-711.

15 Fox AJ, Goldblatt PO, Jones DR. Social class mortality differentials: artefact, selection or life circumstances. I Epidemiol Community Health 1985;39:1-8.

16 Pearlin LJ, Menaghan EG, Liebermann MA, Mullan JT. The stress process. I Health Soc Behav $1981 ; 22: 337-56$

17 Atkinson T, Liem R, Liem JH. The social costs of unemployment: implications for social support. J Health Soc Behav 1986;27:317-31.

18 Banks MH, Jackson PR. Unemployment and risk of minor psychiatric disorder in young people: cross-sectional and longitudinal evidence. Psychol Med 1982;12:789-98.

9 Cohen S, Syme SL. Social support and health. Orlando, Florida: Academic Press, 1985.

20 Broadhead WE, Kaplan BH, James SH, et al. The epidemiologic evidence for a relationship Coadhead WE, Kaplan BH, James SH, el al. The epidemin:521-37.

21 Bowling A. Mortality after bereavement: a review of the literature on survival periods and facts affecting survival. Soc Sci Med 1987;24:117-24.

22 Berkman LF, Syme SL. Social networks, host resistance, and mortality: a nine-year follow-up study of Alameda County residents. Am f Epidemiol 1979;109:186-204.

23 Beale N, Nethercott S. Job-loss and family morbidity: a study of a factory closure. $\mathcal{F} R$ Coll Gen Pract 1985;35:510-4.

24 Linn MW, Sandifer R, Stein S. Effects of unemployment on mental and physical health. Am $\mathcal{F}$ Public Health 1985;75:502-6.

25 Kasl S, Cobb S, Brooks GW. Changes in serum uric acid and cholesterol levels in men undergoing job loss. JAMA 1968;206:1500-7.

26 Flemming R, Baum A, Reddy D, Gatchel RJ. Behavioral and biochemical effects of job loss and unemployment stress. $f$ Human Stress 1984;10:12-7.

27 Arnetz BB, Wasserman J, Petrini B, et al. Immune function in unemployed women. Psychosom Med 1987;49:3-12.

28 Donovan A, Oddy M, Pardoe R, Ades A. Employment status and psychological well-being: a longitudinal study of 16-year-old school leavers. $\mathcal{F}$ Child Psychol Psychiatry 1986;27:65-76. 29 Cassel J. The contribution of the social environment to host resistance. Am $\mathcal{F}$ Epidemiol 1976;104:107-23.

(Accepted 11 August 1987)

\section{SHORT REPORTS}

\section{Alcohol consumption and dependence in elderly patients in an urban community}

Much interest has centred recently on the consumption of alcohol and its misuse by young people, but little attention has been paid to the drinking patterns of elderly people in the community and their dependence on alcohol. Drew even suggested that alcohol dependence was self limiting in the elderly because of changing psychological, social, and economic factors. We have conducted a cross sectional survey in an urban community examining alcohol consumption and alcohol dependence.

\section{Methods and results}

Subjects were taken from the age-sex register of a singlehanded general practice in the centre of Newcastle upon Tyne, which had 828 patients over the age of 60 one in six were randomly picked and asked to participate in a general health survey. Of these 138 patients, 101 were interviewed in their homes by one interviewer (RB), 32 refused to take part, and five had not been contacted after at least three calls. No further information was obtained on the non-responders.

A structured questionnaire based on previously validated general population surveys was used ${ }^{2}$; it covered demographic features and questions relating to alcohol consumption and dependence (including the CAGE questionnaire ${ }^{4}$ ). Approval was obtained from the Newcastle District Health Authority and University ethical committee, and data were analysed with the statistical package for the social sciences.

The respondents' mean age was $71 \cdot 3$ (SD 8.1) years (range 60-95 years); 53 were women and 48 men. Patients aged 75 and under made up two thirds of the study population. Altogether $41(85 \%)$ men and $19(36 \%)$ women were married 64 patients were in social class III, the rest being evenly distributed among the other social classes.

Alcohol intake was determined from ratings of quantity and frequency (units/ week) and self assessment; respondents were classified as alcohol dependent if they answered two or more of the four questions on the CAGE questionnaire positively. ${ }^{4}$ Mean weekly alcohol consumption was 16.5 units, men consuming more than women (22.6 $v 10.9$ units/week) and patients 75 and under more than those aged over $75(20.5 v 8.7$ units/week). By the method of classification of the general household survey $13(27 \%)$ of men and five $(9 \%)$ women were heavy drinkers (table) $)^{2}$ compared with eight $(16 \%)$ and five $(10 \%)$, respectively, by that of the Office of Population Censuses and Surveys. ${ }^{3}$ Overall $31 \%$ claimed to be

Classification of types of elderly drinker by sex and age (figures are numbers (percentages) of patients)

\begin{tabular}{llclccc}
\hline & \multicolumn{2}{c}{ Sex } & & \multicolumn{2}{c}{ Age (years) } & \\
\cline { 2 - 5 } Type of drinker & Men & Women & & $\leqslant 75$ & $>75$ & Total \\
\hline Abstainer & $4(8)$ & $12(23)$ & & $9(13)$ & $7(21)$ & 16 \\
Occasional & $6(13)$ & $7(13)$ & & $7(11)$ & $6(18)$ & 13 \\
Infrequent light & $4(9)$ & $11(21)$ & & $6(9)$ & $8(23)$ & 15 \\
Frequent light & $14(29)$ & $15(28)$ & & $22(33)$ & $8(23)$ & 29 \\
Moderate & $7(14)$ & $3(6)$ & & $9(13)$ & $1(3)$ & 10 \\
Heavy & $13(27)$ & $5(9)$ & & $14(21)$ & $4(12)$ & 18 \\
\hline Total & 48 & 53 & 67 & 34 & 101 \\
\hline
\end{tabular}

«By general household survey classification. ${ }^{2}$

abstainers by the Office of Population Censuses and Surveys criteria, 16 by those of the general household survey, and 21 by self categorisation; only two thought they drank heavily. Forty two respondents said they had decreased their alcohol intake since they were 60 , but 12 had increased it. The CAGE questionnaire classified 17 patients as having problems related to alcohol (11 men (23\%), six women $(11 \%)$ ). Patients classified as being alcohol dependent drank 38.0 (SD $27 \cdot 0)$ units/week compared with $12 \cdot 3(6 \cdot 3)$ units/week for those not dependent on alcohol $(\mathrm{p}<0 \cdot 02)$. 